\title{
Consenso sobre a Síndrome de Abstinência do Álcool (SAA) e o seu tratamento
}

\author{
Ronaldo Laranjeira (SP), Sérgio Nicastri (SP), Claudio Jerônimo (SP), Ana C Marques (SP) e equipe* \\ Departamento de Dependência Química da Associação Brasileira de Psiquiatria
}

\section{Apresentação}

O corpo do conhecimento médico vem crescendo exponencialmente ao longo das últimas décadas, o que torna a boa prática da medicina um exercício cada vez mais difícil devido à constante necessidade de avaliar o que vale a pena continuar fazendo para o bem de nossos pacientes. Várias novas idéias surgiram com o objetivo de ajudar a organizar o conhecimento médico: "medicina baseada em evidências", "revisão sistemática da literatura", "educação médica continuada". Além disso, os meios eletrônicos facilitaram muito o acesso à informação, criando a sensação de que existe um mundo de novas informações e que o médico não tem tempo para atualizar-se.

No entanto, nenhum profissional isoladamente consegue fazer uma revisão consistente da literatura de todos os assuntos da sua prática clínica devido à dificuldade de tempo e muitas vezes de conhecimento. Nesse sentido, as associações médicas têm um papel fundamental em auxiliar seus afiliados com revisões sistemáticas da literatura que auxiliem o clínico a organizar-se frente a essa avalanche de informações. Nos últimos anos temos vistos vários consensos surgirem na literatura internacional. No nosso meio, recentemente a Associação Médica Brasileira (AMB) considerou a criação de consensos como uma das suas mais importantes metas para a nova gestão.

O Departamento de Dependência Química da Associação Brasileira de Psiquiatria optou por começar pela Síndrome de Abstinência do Álcool, pois considerou-se que é um assunto no qual na prática clínica ainda não existe uma homogeneidade de procedimentos aqui no Brasil, muito embora a literatura internacional aponte para uma quase unanimidade sobre o que fazer e principalmente sobre o que não fazer.

Devido à falta de experiência sobre esse tipo de atividades tentamos ser o mais cuidadosos possível e para tanto adotamos a seguinte estratégia: em primeiro lugar foram identificados os profissionais com maior experiência clínica e científica em dependência química. Tentou-se buscar a melhor distribuição possível entre as diferentes regiões do Brasil. Foi feita uma revisão da literatura por meio da Medline e pedido para que alguns dos participantes fizessem um resumo crítico de algumas partes do consenso. Durante um final de semana inteiro esses profissionais reuniram-se e discutiram a melhor forma de produzir o consenso. Após extensa discussão foi formada uma comissão encarregada de fazer o texto final. Esse texto foi enviado para cada um dos participantes para a aprovação final.

O objetivo agora, após a publicação na Revista Brasileira de Psiquiatria, é divulgar esse consenso o máximo possível. Temos a intenção de que esse texto possa estar a disposição de todos os clínicos brasileiros que tenham a possibilidade de tratar alguém com a síndrome de abstinência do álcool.

Ronaldo Laranjeira Coordenador do consenso

\section{Introdução}

Pessoas que bebem de forma excessiva, quando diminuem o consumo ou se abstêm completamente, podem apresentar um conjunto de sintomas e sinais, denominados Síndrome de Abstinência do Álcool (SAA). Alguns sintomas, como tremores, são típicos da SAA. Entretanto, muitos outros sintomas e sinais físicos e psicológicos considerados como parte da SAA são insidiosos, pouco específicos, o que torna o seu reconhecimento e a sua avaliação processos complexos, muito mais do que possa ser pensado num primeiro momento.

Uma série de fatores influenciam o aparecimento e a evolução dessa síndrome, entre eles: a vulnerabilidade genética, o gênero, o padrão de consumo de álcool, as características individuais biológicas e psicológicas e os fatores socioculturais. Os sintomas e sinais variam também quanto à intensidade e à gravidade, podendo aparecer após uma redução parcial ou total da dose usualmente utilizada, voluntária ou não, como, por exemplo, em indivíduos que são hospitalizados para tratamento clínico ou cirúrgico. Os sinais e sintomas mais comuns da SAA são: agitação, ansiedade, alterações de humor (irritabilidade, disforia), tremores, náuseas, vômitos, taquicardia, hipertensão arterial, entre outros. Ocorrem complicações como: alucinações, o Delirium Tremens (DT) e convulsões.

Este consenso visa orientar o profissional de saúde na avaliação, diagnóstico e tratamento da SAA e também das complicações clínicas e psiquiátricas associadas. O manejo da SAA é o primeiro passo no tratamento da dependência do álcool e representa um momento privilegiado para motivar o paciente a permanecer em seguimento.

\footnotetext{
* Analice Gigliotti (RJ), Ângelo Campana (RS), Benedito Bezerra (PA), Cláudia Maciel (MG), Cristina Del Bem (SP), Dagoberto Requião (PR), Ernani Luz (RS), Fabio Gomes de Matos e Souza (CE), Florence Kerr-Correa (SP), João Carlos Dias (RJ), João Checker Bou-Habib (ES), Marcos Zaleski (SC), Maria da Penha Zago (ES), Perpétua Nóbrega (SP), Renato Mussi (RJ), Ruy Palhano (PI) e Sérgio de Paula Ramos (RS)
} 


\section{Bases biológicas}

As dificuldades em estabelecer um tratamento farmacológico mais eficaz para a SAA estão ligadas a um, ainda incompleto, entendimento do funcionamento dos neurotransmissores ligados à dependência e à síndrome de abstinência do álcool. $\mathrm{O}$ aumento da eficácia e da resposta terapêutica de novas drogas está diretamente relacionado à compreensão dos mecanismos de ação do etanol e dos seus efeitos nos diferentes sistemas de neurotransmissão que ocorrem no sistema nervoso central (SNC). O que se conhece dos sintomas da SAA tem sido explicado pelo fenômeno de neuroadaptação que ocorre no SNC, quando há exposição crônica ao etanol. Tais mecanismos e a associação com as manifestações neurofisiológicas serão descritos a seguir.

\subsection{SAA e monoaminas}

Os sintomas e sinais da SAA estão relacionados à alteração nos níveis de liberação de noradrenalina e dopamina. A hiperestimulação adrenérgica, que pode ser intensa na SAA, deve-se a uma redução da atividade de adrenoreceptores inibitórios pré-sinápticos do subtipo $\alpha_{2}{ }^{1}$ um fenômeno conhecido como down-regulation.

A hiperatividade de receptores NMDA (N-Metil-DAspartato) também está relacionada ao aumento da liberação noradrenérgica no locus ceruleus de ratos, observada após a retirada do álcool. ${ }^{2}$ Alguns trabalhos demonstram que a liberação de dopamina, durante a SAA, apresenta queda a níveis inferiores aos observados no período anterior à exposição crônica ao álcool, por cessação do disparo dopaminérgico na área tegmental ventral. ${ }^{3,4}$ Esses efeitos são responsáveis por um grande número de reações fisiológicas, tais como: ${ }^{5,6}$

- taquicardia por ativação de receptores beta-adrenérgicos;

- hipertensão por ativação de vias alfa-adrenérgicas;

- aumento da força de contração do músculo cardíaco por ação adrenérgica inotrópica positiva;

- náuseas e vômitos devido à redução do esvaziamento gástrico;

- piloereção;

- midríase;

- tremores pela facilitação da neurotransmissão muscular;

- aumento do consumo de oxigênio;

- aumento da temperatura corporal em até $2^{\circ} \mathrm{C}$.

\section{2. SAA e aminoácidos neurotransmissores}

$\mathrm{O}$ etanol atua como um antagonista dos receptores NMDA (N-Metil-D-Aspartato), um receptor do tipo excitatório do SNC. ${ }^{7,8} \mathrm{O}$ consumo crônico de bebidas alcoólicas provoca um aumento da densidade desses receptores. ${ }^{9}$ Estudos em animais têm demonstrado que esse aumento persiste por cerca de 36 horas após a retirada do etanol, período que coincide com o aparecimento das crises convulsivas, fenômeno neurotóxico relacionado à hiperatividade glutamatérgica.

$\mathrm{Na}$ SAA há uma hipoatividade GABAérgica. Os receptores GABA $_{A}$ têm uma atividade inibitória e, a medida que deixam de exercer sua atividade durante a SAA, há uma estimulação do SNC. Essa hipoatividade é funcional, uma vez que, diferente- mente do que ocorre com os receptores NMDA, não há evidências de alteração no número de receptores $\mathrm{GABA}_{\mathrm{A}}$ durante a exposição crônica ao álcool. ${ }^{10,11}$ Há uma redução da densidade de mRNA relacionada ao local de ação dos benzodiazepínicos e do etanol.

\section{3. SAA e canais de cálcio}

Com a exposição crônica ao etanol, há uma alteração nos canais de cálcio do tipo L, um dos vários canais de cálcio mais conhecidos. A ação do cálcio nos terminais nervosos é fundamental para a liberação dos neurotransmissores na fenda sináptica. Diversos estudos têm demonstrado que a administração crônica de etanol leva a uma redução na atividade dos canais de cálcio do tipo L, reduzindo a atividade elétrica dentro do neurônio e, assim, reduzindo a ação de neurotransmissores. ${ }^{12}$

As alterações na neurotransmissão e os sintomas correspondentes a cada neurotransmissor envolvido na SAA estão representados na Figura 1.

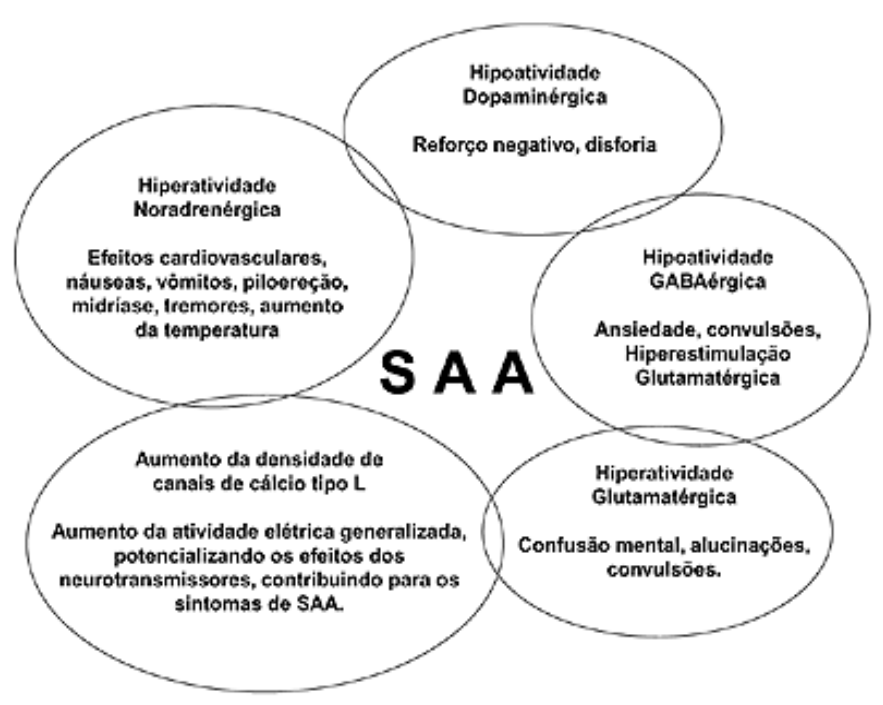

Figura 1 - Bases biológicas dos sinais e sintom as da SAA

\section{Diagnóstico}

A redução ou a interrupção do uso do álcool em pacientes dependentes produz um conjunto bem definido de sintomas chamado de síndrome de abstinência. Embora alguns pacientes possam experimentar sintomas leves, existem aqueles que podem desenvolver sintomas e complicações mais graves, levando-os até a morte.

O quadro se inicia após 6 horas da diminuição ou da interrupção do uso do álcool, quando aparecem os primeiros sintomas e sinais. São eles: tremores, ansiedade, insônia, náuseas e inquietação. Sintomas mais severos ocorrem em aproximadamente $10 \%$ dos pacientes e incluem febre baixa, taquipnéia, tremores e sudorese profusa. Em cerca de 5\% dos pacientes não tratados, 
as convulsões podem se desenvolver. Outra complicação grave é o delirium tremens (DT), caracterizado por alucinações, alteração do nível da consciência e desorientação. A mortalidade nos pacientes que apresentam DT é de 5 a $25 \% .{ }^{13} \mathrm{O}$ aparecimento dos sintomas em relação ao tempo após interrompido o uso de bebida alcóolica e a porcentagem dos pacientes que apresentam sintomas da SAA estão ilustrados na Figura 2.
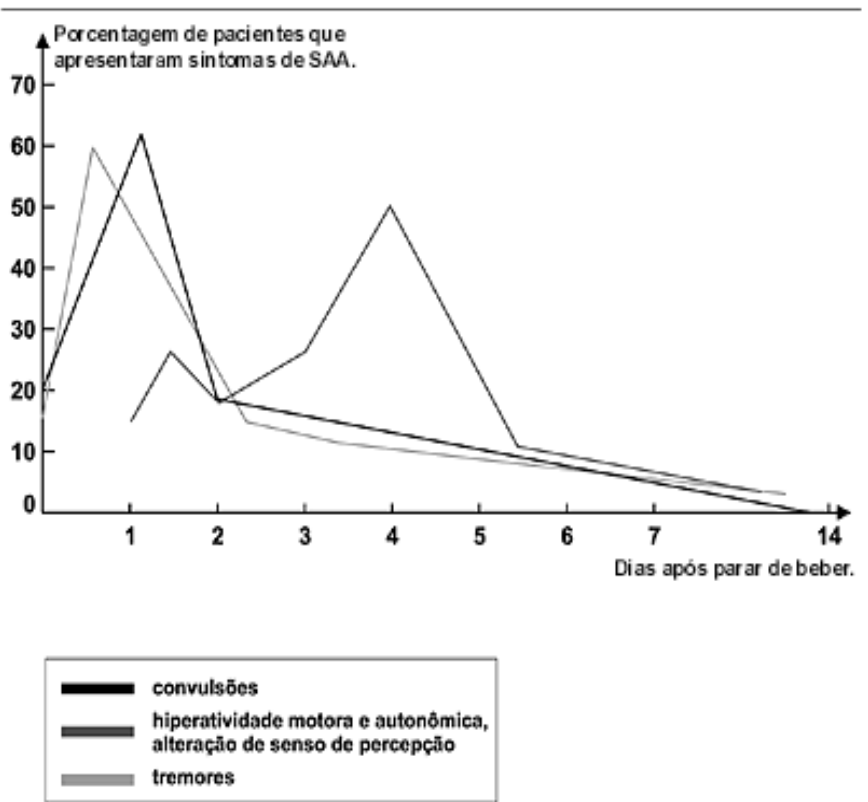

Fonte: Adaptado de Vitor e Adams, 1953 ( in Trevisam e col, 1998).

Figura 2 - Relação entre a interrupção do uso de bebida alcoólica e o aparecimento de sintomas como tremores, al ucinaçöes e delirium tremens

\section{Critérios diagnósticos}

Os critérios da Classificação Internacional das Doenças em sua décima revisão, CID-10, foram adotados neste consenso como diretrizes no diagnóstico da SAA.

\subsection{F 10.3: Síndrome de abstinência}

Um conjunto de sintomas, de agrupamento e gravidade variáveis, ocorrendo em abstinência absoluta ou relativa do álcool, após uso repetido e usualmente prolongado e/ou uso de altas doses. O início e o curso do estado de abstinência são limitados no tempo e relacionados à dose de álcool consumida imediatamente antes da parada e da redução do consumo. A síndrome de abstinência pode ser complicada com o aparecimento de convulsões. Os sintomas mais freqüentes são: hiperatividade autonômica; tremores; insônia; alucinações ou ilusões visuais, táteis ou auditivas transitórias; agitação psicomotora; ansiedade; e convulsões tipo grande mal.

O diagnóstico pode ainda ser mais especificado, utilizandose os seguintes códigos:

F 10.30: Síndrome de abstinência não complicada;

F 10.31: Síndrome de abstinência com convulsões.

A SAA evolui com maior ou menor gravidade e pode ser complicada por delirium tremens, descrito a seguir de acordo com os critérios da CID - 10. Alguns fatores estão associados a uma evolução mais grave, e funcionam como preditores de gravidade da SAA, tais como: história anterior de síndrome de abstinência grave (repetidas desintoxicações); alcoolemia alta sem sinais clínicos de intoxicação; sintomas de abstinência com alcoolemia alta; uso de tranqüilizantes e hipnóticos;e associação de problemas clínicos e psiquiátricos.

\section{2. F 10.4: Síndrome de abstinência com delirium tremens (DT)}

Delirium tremens induzido por álcool deve ser codificado aqui. DT é um estado confusional breve, mas ocasionalmente com risco de vida, que se acompanha de perturbações somáticas. É usualmente conseqüência de uma abstinência absoluta ou relativa de álcool em usuários gravemente dependentes, com uma longa história de uso. O início usualmente ocorre após abstinência de álcool. Em alguns casos o transtorno aparece durante um episódio de consumo excessivo de bebidas alcoólicas, em cujo caso deve ser codificado aqui. Os sintomas prodrômicos tipicamente incluem: insônia, tremores e medo. $\mathrm{O}$ início pode também ser precedido de convulsões por abstinência. A clássica tríade de sintomas inclui obnubilação de consciência, confusão, alucinações e ilusões vívidas, afetando qualquer modalidade sensorial e com tremores marcantes. Delírios, agitação, insônia ou inversão do ciclo do sono e hiperatividade autonômica estão também usualmente presentes.

Exclui: Delirium não induzido por álcool.

\subsubsection{Curso do delirium tremens}

Instalação: 1 a 3 dias.

Duração: 1 semana a dois meses (maioria entre 10 e 12 dias).

Idosos: curso mais prolongado; maior risco de mortalidade; maior número de complicações; mais freqüentemente a recuperação não é total.

\section{Avaliação do paciente}

A avaliação inicial de um paciente que refere uso crônico de álcool deve ser muito cuidadosa e detalhada. ${ }^{14} \mathrm{~A}$ partir dessa investigação criteriosa é possível que se determine o nível de comprometimento no momento da intervenção, os problemas relacionados a esse uso e à presença ou não de complicações e comorbidades associadas. ${ }^{15}$ Essa etapa determinará um diagnóstico mais preciso e um encaminhamento mais adequado para o tratamento subsequiente e, portanto, ela deve ser direcionada por dois vetores fundamentais: (1) a avaliação da SAA e (2) a avaliação dos problemas associados ou não ao consumo (Figura 3).

\subsection{Avaliação da síndrome de abstinência do álcool (SAA)}

\subsubsection{Anamnese}

Uma história completa sobre o paciente, levando em conta suas várias dimensões, deve ser recolhida, com o objetivo de avaliar o paciente como um todo. Não existem sinais ou sintomas patognomônicos da SAA. Ela é uma síndrome e, portanto, todas as condições clínicas associadas e os diagnósticos dife- 


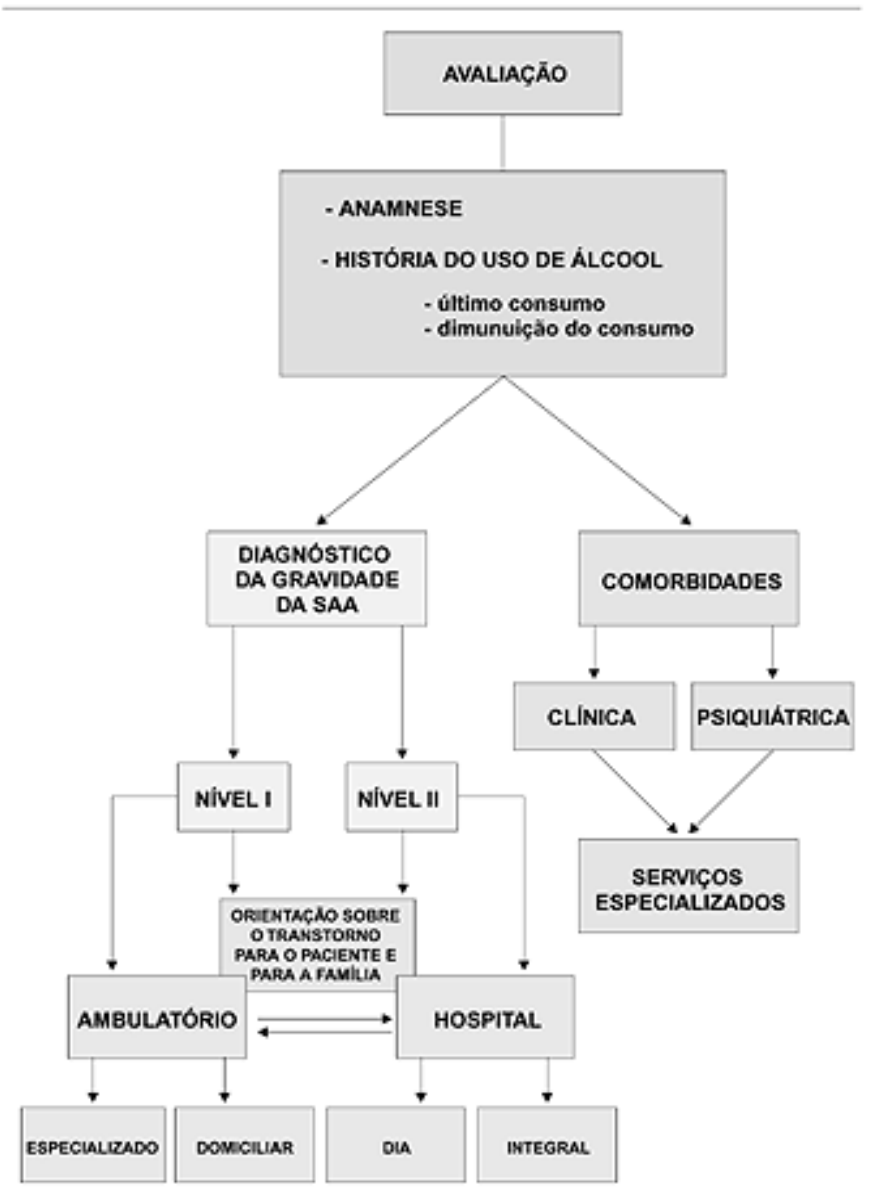

Figura 3 - Avaliação do paciente

renciais deverão ser buscados nessa etapa inicial. A maior parte das complicações associadas à SAA ocorrem devido a uma avaliação inadequada. Um paciente com SAA quase sempre tem alguma outra intercorrência clínica associada.

\subsubsection{História do uso de álcool}

Deve-se buscar informações básicas sobre o padrão de consumo dos últimos anos, avaliando a quantidade e a freqüência do beber. Além disso, o padrão de consumo mais recente deve ser cuidadosamente investigado, em especial o último consumo ou diminuição dele (ver sinais e sintomas da SAA). O diagnóstico pelo CID-10 de uso nocivo ou dependência do álcool deve ser buscado.

A partir do diagnóstico da SAA, dois tipos de avaliações mais pormenorizadas deverão ser as próximas etapas: o diagnóstico da gravidade da SAA e o diagnóstico de eventuais comorbidades clínicas e/ou psiquiátricas. Levando em consideração sua complexidade, classificou-se o comprometimento do usuário em dois níveis: leve/moderado e grave. Essa categorização referendará o paciente para o melhor tratamento, de acordo com a disponibilidade da rede de serviços de saúde de cada local e de seu sistema familiar/social.

Considerou-se nesse consenso, para a determinação dos níveis de comprometimento do indivíduo pelo álcool, aspectos biológicos, psicológicos e sociais decorrentes do uso da substância. Os aspectos comórbidos também foram considerados, pois influenciam diretamente a SAA. Essa visão biopsicossocial da síndrome de abstinência decorre do próprio conceito de síndrome de dependência e permite um diagnóstico mais amplo e adequado. ${ }^{16} \mathrm{O}$ encaminhamento para o tratamento subseqüente será realizado, ajustando-se o tipo de intervenção às necessidades de cada paciente, aplicando-se, assim, o pareamento. ${ }^{17}$

Levando em consideração a complexidade do diagnóstico, é possível classificar o comprometimento do usuário crônico de álcool em dois níveis: leve/moderado e grave. A partir dessa classificação, o paciente será encaminhado para o melhor tratamento, de acordo, também, com a disponibilidade da rede de serviços de saúde de cada local. O paciente poderá apresentar um comprometimento em:

Nível I - Quando o comprometimento é leve/moderado e, portanto, apresenta uma síndrome de abstinência leve/moderada, compreendendo os seguintes aspectos:

- Biológicos: leve agitação psicomotora; tremores finos de extremidades; sudorese facial discreta; episódios de cefaléia; náuseas sem vômitos; sensibilidade visual, sem alteração da percepção auditiva e tátil.

- Psicológicos: o contato com o profissional de saúde está íntegro; o paciente encontra-se orientado temporoespacialmente; o juízo crítico da realidade está mantido; apresenta uma ansiedade leve; sem relato de episódio de violência auto ou heterodirigida.

- Sociais: mora com familiares ou amigos e essa convivência está regular ou boa; sua atividade produtiva vem sendo desenvolvida, mesmo que atualmente esteja desempregado/ afastado, a rede social está mantida.

- Comórbidos: sem complicações e/ou comorbidades clínicas e/ou psiquiátricas graves detectadas ao exame clínico-psiquiátrico geral.

Para os pacientes classificados como nível I a intervenção deverá ser psicoeducacional e clínica, isso é, o paciente deve ser informado com clareza sobre o diagnóstico, recebendo orientações sobre a dependência do álcool e sobre a síndrome de abstinência, além de tratamento específico para a fase de privação aguda de acordo com a necessidade. $\mathrm{O}$ encaminhamento será direcionado para o tratamento ambulatorial especializado, com ou sem desintoxicação domiciliar. ${ }^{18}$

Nível II - Quando o comprometimento é grave e, portanto, apresenta uma síndrome de abstinência grave com os seguintes aspectos:

- Biológicos: agitação psicomotora intensa; tremores generalizados; sudorese profusa; cefaléia; náuseas com vômitos; sensibilidade visual intensa; quadros epiletiformes agudos ou relatados na história pregressa.

- Psicológicos: o contato com o profissional de saúde está prejudicado; o paciente encontra-se desorientado temporoespacialmente; o juízo crítico da realidade está comprometido; apresenta-se com uma ansiedade intensa; refere história de violência auto ou heterodirigida; o pensamento está descontínuo, rápido e de conteúdo desagradável e deli- 
rante; observam-se alucinações auditivas, táteis ou visuais.

- Sociais: o relacionamento com familiares ou amigos está ruim; tem estado desempregado, sem desenvolver qualquer atividade produtiva; a rede social de apoio é inexistente ou restrita ao ritual de uso do álcool; não possui familiares auxiliando no tratamento.

- Comórbidos: com complicações e/ou comorbidades clínicas e/ou psiquiátricas graves detectadas ao exame geral.

Para os pacientes nível II, a emergência clínica-psiquiátrica será a melhor intervenção, solicitando-se a presença imediata de familiares ou amigos para orientação quanto à gravidade do quadro. O paciente será encaminhado para tratamento hospitalar especializado, sendo que a família deverá receber uma intervenção psicoeducacional sobre o transtorno, concomitantemente.

A Figura 4 sintetiza os níveis de gravidade da SAA.

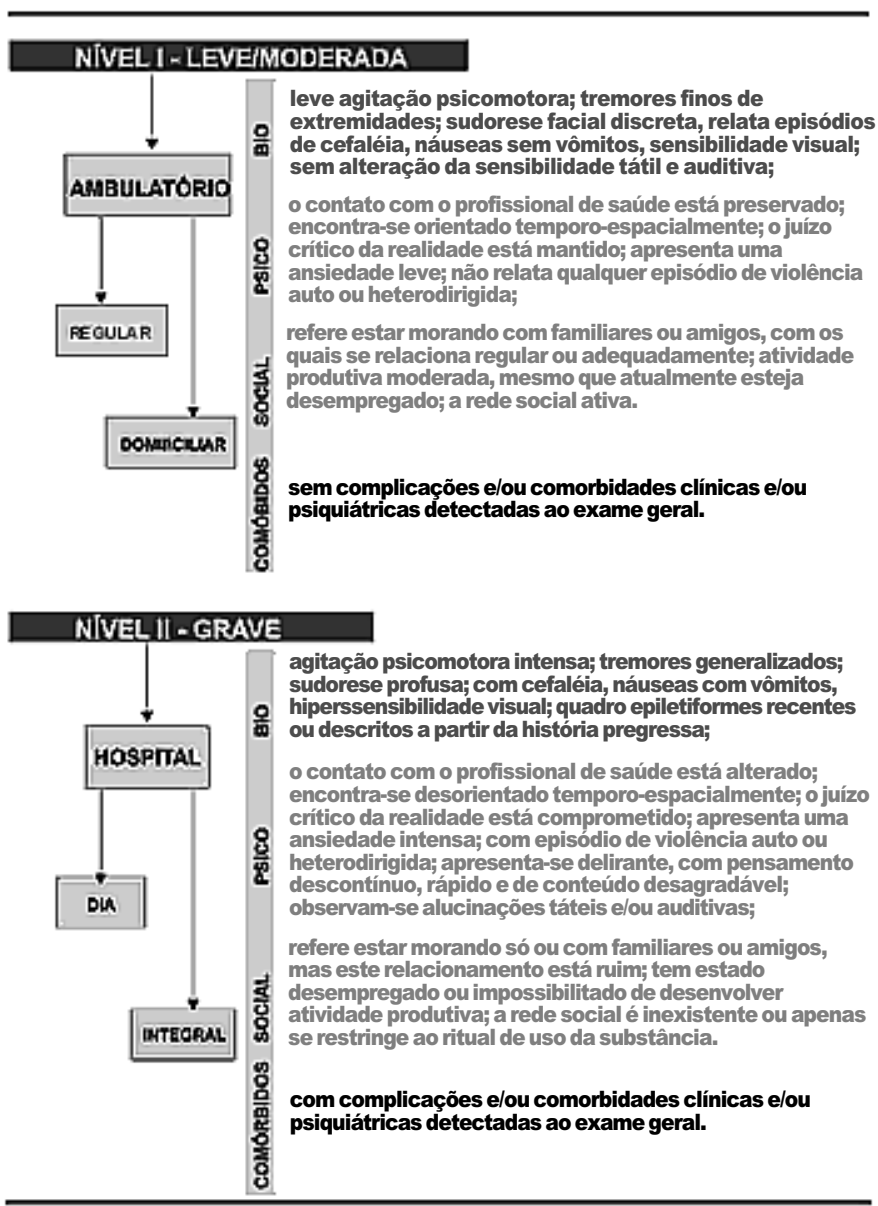

Figura 4 - Níveis de gravidade da SAA

\section{Orientação familiar}

Educação em saúde é fundamental para assegurar não só o entendimento do cliente, como também de sua família, sobre os problemas relacionados ao uso crônico de álcool. Assim como é imprescindível a orientação do paciente sobre o seu problema, a família, parte integrante dessa disfunção, precisa ser informada e encaminhada para um tratamento mais intensivo, se necessário.
Em qualquer dos níveis de comprometimento que o indivíduo se apresente, é essencial trabalhar os conceitos de síndrome de dependência e abstinência alcoólica, com objetivo claro de desenvolver, nesse sistema familiar, a crítica sobre seu papel nesse transtorno, como também promover sua mudança de pensamento e comportamento. Trabalhar a auto- estima e a importância da desintoxicação, assim como a prevenção da recaída, são estratégias a serem adotadas nessa fase inicial do tratamento, não só com o paciente, como também com seu sistema familiar e social.

\section{Pareamento}

A idéia da avaliação dos tratamentos em todos os países é muito clara, pois todos concordam que não há uma forma de tratamento única e ideal para todas as pessoas com problemas devidos ao uso do álcool e de outras drogas. ${ }^{19}$ A escolha do melhor tratamento depende de um diagnóstico precoce e adequado, e isso decorre de uma metodologia de avaliação rigorosamente organizada. Atualmente, esse é o principal desafio nas pesquisas em desenvolvimento. ${ }^{20}$

Portanto, diferenciar os tratamentos e parear os indivíduos de acordo com suas peculiaridades podem melhorar o resultado da intervenção. ${ }^{21} \mathrm{O}$ pareamento do paciente com o tipo de abordagem, como uma forma de melhorar a efetividade, foi sugerido desde Jellinek em 1941. Para o sucesso da proposta de tratamento, muitos aspectos têm que ser levados em consideração. ${ }^{22}$ Aproximar as características do tratamento com as peculiaridades do paciente pode determinar resultados diferentes em relação à efetividade. ${ }^{23}$ Assim, não existe uma forma única de tratamento, nem a melhor. Cada vez mais, a idéia de parear o paciente segundo suas características pessoais e o tipo de abordagem vêm orientando os diversos serviços na busca de uma efetividade satisfatória e de uma melhor relação custo-benefício. ${ }^{17}$

O ambulatório é uma intervenção não intensiva, menos estruturada, em relação à internação, pois utiliza menos recursos. É segura e menos dispendiosa, sendo considerada a mais popularmente difundida, tratando $90 \%$ dos pacientes dependentes de álcool. ${ }^{24}$ Para pacientes com síndrome de abstinência leve/moderada, sem comorbidades clínicas e/ou psiquiátricas graves, essa intervenção é adequada e sem riscos. É um tratamento menos estigmatizante, promovendo a manutenção do indivíduo no seu sistema familiar, social e profissional, além de possibilitar a participação mais ativa da família no tratamento..$^{25-27}$

O hospital é um tratamento mais estruturado e intensivo e, portanto, mais custoso, mas tem se mostrado tão efetivo como o ambulatório. Está indicado para pacientes com síndrome de abstinência grave; em casos de comorbidades clínicas e/ou psiquiátricas graves com remissão prolongada; em dependentes graves que não se beneficiaram de outras intervenções; para aqueles que usam múltiplas substâncias psicotrópicas, e também para aqueles que apresentam comportamento auto ou heteroagressivo. A disfunção grave de sistema familiar e social pode ser determinante de encaminhamento para o modelo hospitalar. ${ }^{28,29}$

\section{Comorbidades}

As principais complicações e/ou comorbidades clínicas as- 
sociadas à SAA estão descritas nas tabelas abaixo e devem ser pesquisadas.

Tabela 1 - Principais complicações e/ou comorbidades clínicas associadas à SAA

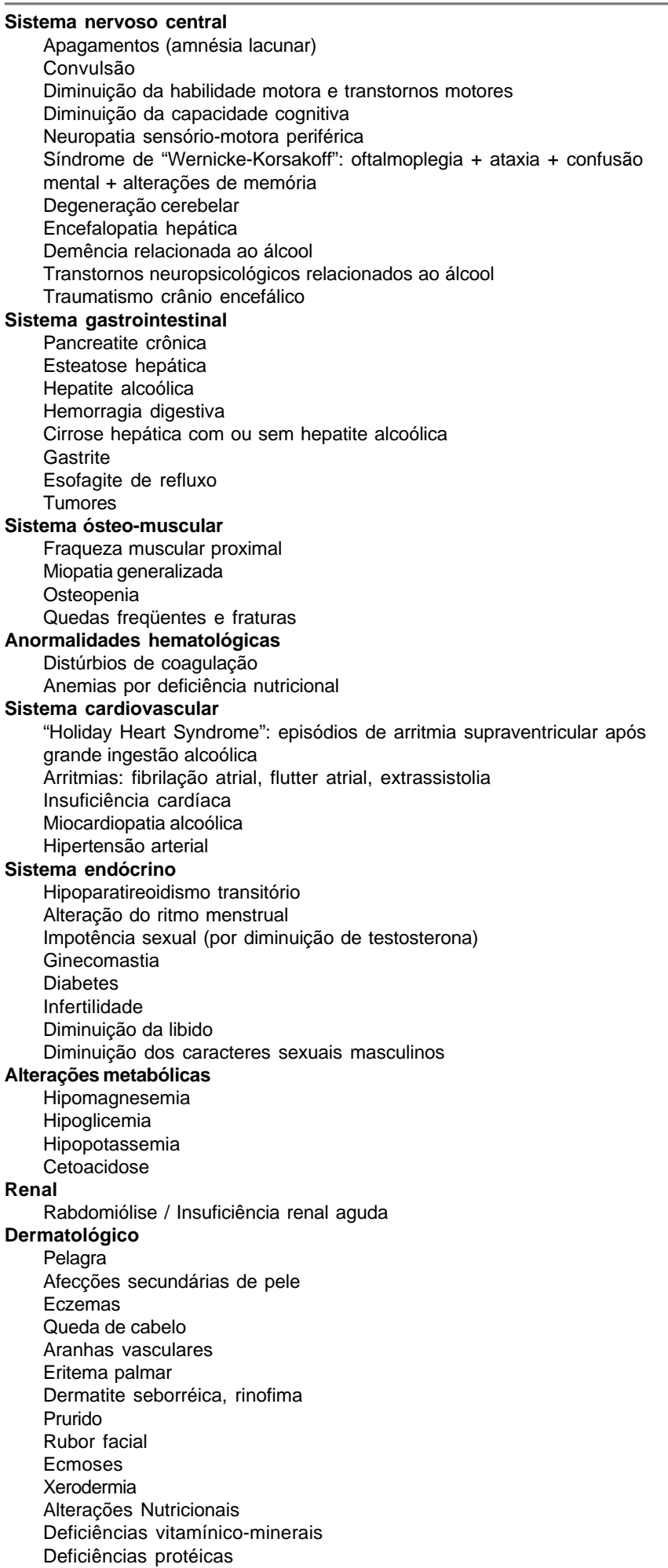

Tabela 2 - Principais comorbidades e/ou complicações psiquiátricas

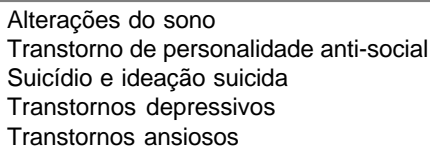

\section{Diagnóstico diferencial}

Abaixo estão listadas as principais condições clínicas que deveriam ser levadas em consideração como diagnóstico diferencial da SAA.

Tabela 3 - Principais condições clínicas que deveriam ser levadas em consideração como diagnóstico diferencial da SAA

Infecções (pneumonia, meningite, encefalite)

Traumatismo crânio-encefálico, hematoma subdural

Encefalopatia hepática, má nutrição

Efeitos adversos de outros medicamentos

Com convulsões: tumor, alterações minerais ou hidroeletrolíticas,

traumatismo craniano

Com DT: outras causas de delirium

\section{Avaliação laboratorial}

Para complementar a avaliação inicial é necessário que se realize alguns exames laboratoriais com o objetivo de investigar adequadamente as alterações orgânicas decorrentes da dependência do álcool e que influenciam a síndrome de abstinência. Os exames indicados são: o volume corpuscular médio (VCM); os níveis das enzimas hepáticas (TGO,TGO,GGT); e eletrólitos, como o magnésio, o sódio e o potássio.

Para o diagnóstico diferencial das complicações podem ser solicitados outros exames: radiografia ou ultrassonagrafia de tórax, abdome e/ou crânio ou tomografia computadorizada de crânio.

\section{Tratamento}

Os objetivos do tratamento da síndrome de abstinência do álcool são: 1 . o alívio dos sintomas existentes; 2 . a prevenção do agravamento do quadro com convulsões e delirium; 3. a vinculação e o engajamento do paciente no tratamento da dependência propriamente dita; 4 . a possibilidade de que o tratamento adequado da SAA possa prevenir a ocorrência de síndromes de abstinência mais graves no futuro.

\subsection{Planejamento geral do tratamento}

Serão considerados três níveis de atendimento, com complexidade crescente: tratamento ambulatorial, internação domiciliar e internação hospitalar. O tratamento pode ser dividido em não-farmacológico (que inclui os cuidados gerais e orientações) e farmacológico. Esse último pode ser subdividido em tratamento farmacológico clínico (como a reposição de vitaminas) e psiquiátrico (uso de substâncias psicoativas).

Dentre as medidas do tratamento não-farmacológico, destacamos o monitoramento freqüente do paciente; tentativas 
de propiciar um ambiente tranqüilo, não estimulante, com luminosidade reduzida; fornecimento de orientação ao paciente (com relação a tempo, local, pessoal e procedimentos); limitação de contatos pessoais; atenção à nutrição e à reposição de fluidos; e reasseguramento dos cuidados e encorajamento positivo.

Embora haja consenso sobre a necessidade da reposição de vitaminas (sobretudo a tiamina) durante o tratamento da SAA, ainda existe controvérsia a respeito de doses preconizadas e mesmo quais as vitaminas a serem repostas. A absorção oral de medicamentos pode estar prejudicada nos primeiros dias da SAA, devendo, portanto, proceder a administração parenteral nesse período.

Dentre os psicofármacos utilizados, os benzodiazepínicos (BZD) são a medicação de primeira escolha para o controle dos sintomas da SAA. De modo geral, os compostos de ação longa são preferíveis, sendo os de ação curta mais indicados nos casos de hapatopatia grave. Esquemas de administração são planejados de acordo com a intensidade dos sintomas, pois permitem uma utilização de doses menores de medicação, quando comparados aos esquemas posológicos fixos. Ou seja, devemos buscar a dose adequada para a intensidade de sintomas de cada paciente.

\subsubsection{Tratamento ambulatorial}

Ao receber o paciente, a atitude do profissional de saúde deve ser acolhedora, empática e sem preconceitos. O tratamento da SAA (quadro agudo) é um momento privilegiado para motivar o paciente para o tratamento da dependência (quadro crônico). Deve-se esclarecer a família e, sempre que possível, o próprio paciente sobre os sintomas apresentados, sobre os procedimentos a serem adotados e sobre as possíveis evoluções do quadro. Deve ser propiciado ao paciente e à família o acesso facilitado a níveis mais intensivos de cuidados (serviço de emergência, internação) em casos de evolução desfavorável do quadro. É importante ainda reforçar a necessidade de comparecimento nas consultas remarcadas, que serão tão freqüentes quanto possível, nos primeiros 15 dias do tratamento.

Abordagem não-farmacológica:

- Orientação da família e do paciente quanto à natureza do problema, tratamento e possível evolução do quadro;

- Propiciar ambiente calmo, confortável e com pouca estimulação audiovisual;

- A dieta é livre, com atenção especial à hidratação;

- O paciente e a família devem ser orientados sobre a proibição do ato de dirigir veículos;

- As consultas devem ser marcadas o mais brevemente possível para reavaliação.

Abordagem farmacológica:

- Reposição vitamínica: tiamina intramuscular, nos primeiros 7-15 dias; após esse período a via é oral. Doses de $300 \mathrm{mg} /$ dia de tiamina são recomendadas com o objetivo de evitar a Síndrome de Wernicke, que cursa com ataxia, confusão mental e anormalidades de movimentação ocu- lar extrínseca (essa última, nem sempre presente);

- Benzodizepínicos (BDZs): a prescrição deve ser baseada em sintomas. Dessa forma, as doses recomendadas são as que, em média, o paciente pode receber num determinado dia. O paciente e os familiares devem ser informados a respeito dos sintomas a serem monitorados e orientados sobre a conveniência de utilizar a maior dosagem da medicação à noite. Se houver qualquer sintoma de dosagem excessiva de BZD, como sedação, deve-se proceder a interrupção da medicação. Diazepam: 20mg via oral (VO) por dia, com retirada gradual ao longo de uma semana OU Clordiazepóxido: até $100 \mathrm{mg}$ VO por dia, com retirada gradual ao longo de uma semana. Nos casos de hepatopatias graves: Lorazepam: $4 \mathrm{mg}$ VO por dia, com retirada gradual em uma semana.

Ocorrendo falha (recaída ou evolução desfavorável) dessas abordagens, a indicação de ambulatório deve ser revista, com encaminhamento para modalidades de tratamento mais intensivas e estruturadas.

\subsubsection{Internação domiciliar}

O paciente deve permanecer restrito em sua moradia, com a assistência dos familiares. Idealmente, o paciente deverá receber visitas frequientes de profissionais de saúde da equipe de tratamento. Deve ser propiciado ao paciente e à família o acesso facilitado a níveis mais intensivos de cuidados (serviço de emergência, internação) em casos de evolução desfavorável do quadro.

\section{Abordagem não-farmacológica:}

- A orientação da família deve ter ênfase especial em questões relacionadas à orientação têmporo-espacial e pessoal, níveis de consciência, tremores e sudorese;

- Propiciar ambiente calmo, confortável e com pouca estimulação audiovisual;

- A dieta é leve, desde que tolerada, com atenção especial à hidratação;

- Visitas devem ser restritas, assim como a circulação do paciente.

\section{Abordagem farmacológica:}

- Reposição vitamínica: a mesma recomendada para o tratamento ambulatorial;

- Benzodiazepínicos (BDZs): a prescrição deve ser baseada em sintomas. Dessa forma, as doses recomendadas são as médias que o paciente pode atingir num determinado dia; o paciente e os familiares devem ser informados a respeito dos sintomas a serem monitorados e orientados sobre a conveniência de utilizar a maior dosagem da medicação à noite. Deve-se ressaltar que a dose adequada é aquela que diminui os sintomas da abstinência, e que, portanto, em algumas situações, doses muito maiores do que esta recomendada podem ser indicadas. Diazepam: 40 $\mathrm{mg}$ via oral ( $\mathrm{VO}$ ) por dia, com retirada gradual ao longo de uma semana; ou Clordiazepóxido: $200 \mathrm{mg}$ VO por dia, com retirada gradual ao longo de uma semana. Nos casos de hepatopatias graves: Lorazepam: $8 \mathrm{mg}$ VO por dia, com 
retirada gradual em uma semana.

Na recaída ou evolução desfavorável, está indicado o tratamento hospitalar.

\subsubsection{Tratamento hospitalar}

Essa modalidade é reservada aos casos mais graves, que requerem cuidados mais intensivos. Doses mais elevadas de BZDs são geralmente necessárias e sua prescrição deve ser baseada em sintomas avaliados de hora em hora. Deve ser dada atenção especial à hidratação e correção de distúrbios metabólicos (eletrólitos, glicemia, reposição vitamínica). Em alguns casos, a internação parcial (hospital dia ou noite) pode ser indicada, e, nesses casos, a orientação familiar sobre a necessidade de comparecimento diário deve ser reforçada e a retaguarda para emergências deve ser bem esclarecida. A utilização de "bafômetro", quando esse recurso está disponível, pode ser feita na chegada do paciente na unidade.

\section{Abordagem não-farmacológica:}

- Monitoramento do paciente deve ser freqüente, com aplicação da escala Clinical Institute Withdrawal Assessment for Alcohol, Revised - CIWA-Ar (Anexo), que orienta a avaliação do paciente em relação à gravidade da SAA e a necessidade de administração de medicamentos.

- A locomoção do paciente deve se restrita;

- As visitas devem ser limitadas, pois o ambiente de tratamento deve ser calmo, com relativo isolamento, de modo a ser propiciada uma redução nos estímulos audiovisuais;

- A dieta deve ser leve, quando aceita. Pacientes com confusão mental devem permanecer em jejum, pois existe o risco de aspiração e complicações respiratórias. Nesses casos, deve ser utilizada a hidratação por meio de $1.000 \mathrm{ml}$ de solução glicosada $5 \%$, acrescida de $20 \mathrm{ml}$ de $\mathrm{NaCl} 20 \%$ e $10 \mathrm{ml}$ de $\mathrm{KCl} 19,1 \%$, a cada 8 horas.

Contenção física

Os pacientes agitados que ameaçam violência devem ser contidos, se não forem suscetíveis à intervenção verbal. A contenção deve ser feita por pessoas treinadas, preferivelmente com quatro ou cinco pessoas. É muito importante explicar ao paciente o motivo da contenção.

Os pacientes devem ser contidos com as pernas bem afastadas e com um braço preso em um lado e o outro preso sobre a sua cabeça. A contenção deve ser feita de modo que as medicações possam ser administradas. A cabeça do paciente deve estar levemente levantada para diminuir a sensação de vulnerabilidade e reduzir a possibilidade de aspiração.

A contenção deve ser removida, uma de cada vez a cada cinco minutos, assim que o paciente seja medicado e apresente melhora do quadro de agitação. Todo o procedimento deve ser documentado em prontuário.

Abordagem farmacológica:

- Reposição vitamínica: a mesma recomendada para os níveis anteriores;

- BDZs: a prescrição deve ser baseada em sintomas, avaliados a cada hora pela aplicação da escala CIWA-Ar. Quan- do a pontuação obtida for maior que 8 ou 10, administrar uma das seguintes opções: Diazepam: $10-20 \mathrm{mg}$ VO a cada hora; Clordiazepóxido: 50 - $100 \mathrm{mg}$ VO a cada hora. Nos casos de hepatopatias graves: Lorazepam: 2-4 mg VO a cada hora.

A administração de BDZs por via intravenosa requer técnica específica e retaguarda para manejo de eventual parada respiratória. Deve-se administrar no máximo 10mg de diazepam durante 4 minutos, sem diluição.

\subsection{Manejo das complicações}

Convulsões: a maioria das crises é do tipo tônico-clônica generalizada. As crises convulsivas correspondem a uma manifestação relativamente precoce da SAA, mais de $90 \%$ ocorrem até 48 horas após a interrupção do uso de álcool (pico entre 13 e 24 horas) e estão associadas com evolução para formas graves de abstinência. Cerca de 1/3 dos pacientes que apresentam crises evoluem para delirium tremens, se não forem tratados. Em $40 \%$ dos casos, as crises ocorrem isoladamente. Nos pacientes que apresentam mais de uma crise, elas ocorrem geralmente em número limitado. Quando houver história prévia de epilepsia, devem ser mantidos os medicamentos já utilizados pelo paciente. O diazepam (ou um BDZ de ação longa) é a medicação de escolha, na dose de 10 ou $20 \mathrm{mg}$, via oral. O uso endovenoso é especialmente indicado durante os episódios convulsivos. Não há consenso para a indicação de carbamazepina no tratamento de crises convulsivas da SAA. A literatura não respalda a utilização de defenil-hidantoína (fenitoína) no tratamento dessa complicação da SAA.

Delirium Tremens: forma grave de abstinência, geralmente iniciando-se entre 1 a 4 dias após a interrupção do uso de álcool, com duração de até 3 ou 4 dias. É caracterizado por rebaixamento do nível de consciência, com desorientação, alterações sensoperceptivas, tremores e sintomas autonômicos (taquicardia, elevação da pressão arterial e da temperatura corporal). Doses elevadas de BDZ são necessárias, mas o uso associado de neurolépticos é geralmente indicado. O tratamento farmacológico inclui: diazepam $60 \mathrm{mg}$ por dia (ou lorazepam até $12 \mathrm{mg}$ por dia, em casos de hapatopatia grave) e haloperidol $5 \mathrm{mg}$ por dia. No caso de ocorrer distonia induzida por neurolépticos (particularmente se forem administrados por via parenteral), esse efeito colateral pode ser controlado com o uso de anticolinérgicos (biperideno $2 \mathrm{mg}$ );

Alucinose alcoólica: quadro alucinatório predominantemente auditivo, com sons do tipo cliques, rugidos, barulho de sinos, cânticos e vozes. As alucinações podem ser também de natureza visual e tátil. Os pacientes podem apresentar medo, ansiedade e agitação em decorrência dessas experiências. Uma característica peculiar desse tipo de fenômeno é que ocorre na ausência de rebaixamento do nível de consciência e evolui sem alterações autonômicas óbvias. É tratado com neurolépticos, particularmente o haloperidol $5 \mathrm{mg}$ ao dia, por seu menor potencial de induzir 
convulsões. Neurolépticos podem induzir distonias agudas e outros distúrbios de movimento, que podem ser tratados com anticolinérgicos.

\subsection{O que não fazer}

- A administração de glicose, indiscriminadamente, por risco de ser precipitada a síndrome de Wernicke. A glicose só deve ser aplicada parenteralmente após a administração de tiamina;

- O uso rotineiro de difenil-hidantoína (fenitoína) parenteral, a chamada "hidantalização", uma vez que o uso desse anticonvulsivante não parece ser eficaz no controle de crises convulsivas da SAA;

- A administração de clorpromazina e outros neurolépticos sedativos de baixa potência para controle de agitação, uma vez que podem induzir convulsões. O haloperidol é a indicação mais adequada;

- A contenção física inadequada e indiscriminada, que provoque lesões nos pacientes.

Ao lado, na Figura 5, planos de tratamento, contra-indicações e o manejo das complicações estão resumidos para consulta.

\section{Referências}

1. Nutt DJ, Glue, P, Molyneux S, Clark E. Alpha -2-adrenoceptor activity in alcohol withdrawal: a pilot study of the effects of i.v. clonidine in alcoholics and normals. Alcohol Clin Exp Res 1988;12:14-8.

2. Engberg G, Halos M. Ethanol attenuates the response of locus ceruleos neurons to excitatory amino acid agonists in vivo. Naunym Sch Arch Pharm 1992;345:222-6.

3. Diana M, Gessa GL, Rossetti ZL. Lack of tolerance to ethanolinduced stimulation of dopamine mesolimbic system. Alcohol Alcohol 1992;27(4):329-33.

4. Rossetti ZL, Melis F, Diana M, Gessa GL. Alcohol withdrawal in rats is associated with a marked fall in extraneuronal dopamine. Alcohol Clin Exp Res 1992;16:529-32.

5. Major LF, Hawley RJ, Linnoila M. The role of the central adrenergic system in the mediation of the ethanol intoxication and ethanol witthdrawal syndrome. Psychofarmacol Bull 1984;20(3):487-93.

6. DePetrillo PB, McDonough MK. AWS and the AWS typology. In: Alcohol Withdrawal Treatment Manual. Adobe Trade Markers; 1999. p. 7-17.

7. Carboni S, Isola R, Gessa GL, Rossetti ZL. Ethanol prevents the glutamate release induced by $\mathrm{N}$-methil-D-aspartate receptors in the rat striatum. Neur Letters 1990;152:133-6.

8. Matsumoto I. Molecular neurobiology of alcohol withdrawal. J Neurochem 1998;70(Suppl 2):S45.

9. Rossetti ZL, Carboni S. Ethanol Withdrawal is associated with increased extracellular glutamate in the rat striatum. Eur $\mathrm{J}$ Pharmacol $1995 ; 283(1-3): 177-83$

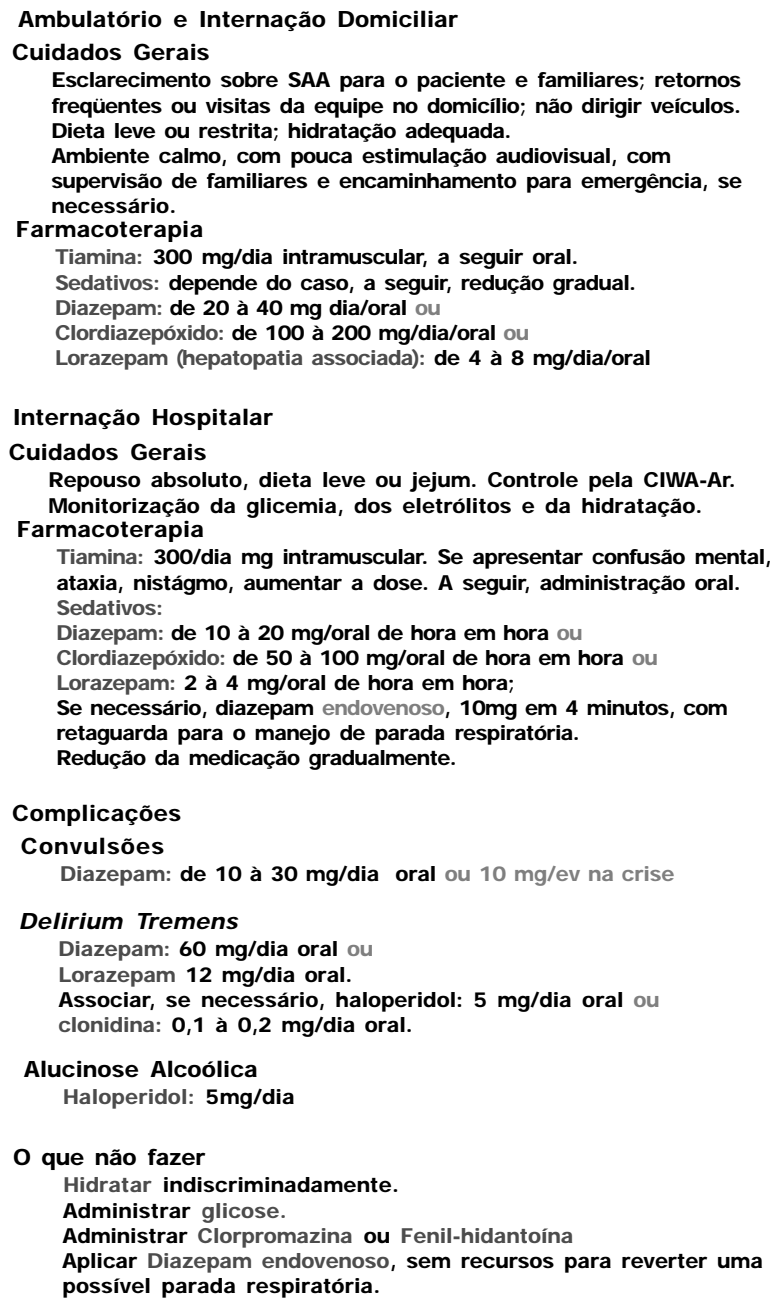

Figura 5 - Tratamento, contra-indicaçóes e manejo das complicaçōes

10. Morrow AL, Montpied P, Lingford-Hughes A, Paul SM. Chronic ethanol and pentobarbital administration in the rat. Alcohol 1990;7:237-44.

11. Devaud LL, Fritschy JM, Sieghart W, Morrow AL. Bi-directional alterations of GABAA receptor subunit peptide levels in rat cortex during chronic ethanol consumption and withdrawal. J Neurochem 1997;69:126-30

12. Lovinger DM. Alcohols and neurotransmitter gated ion channels: past, present and future. Naunym Sch Arch Pharm 1997;356(3):267-82.

13. Trevisan L, Boutros N, Petrakis I, Krystal J. Complications of alcohol withdrawal: pathophysiological insights. Alcohol Health Res World 1998;22(1):61-6.

14. Romach MK, Sellers EM. Management of the Alcohol Withdrawal Syndrome. Annu Rev Med 1991;42:323-40.

15. Williams D, Mcbride A. The drug treatment of alcohol withdrawal symptoms: a systematic review. Alcohol \& Alcoholism 1998;33(2):103-15.

16. [ASAM] American Society of Addiction Medicine, Inc. The principles update series: topics in addiction medicine. Vol 1:2. Detoxification: principles and protocols. Maryland: Chevy Chase; 1997.

17. Mattson ME, Del Boca FK, Carroll KM, Cooney NL, Diclemante CC, Donovan D et al. Compliance with treatment and follow-up protocols in project MATCH: predictors and relationship to outcome. Acohol Clin Exp Res 1994;22(6):1328-39.

18. Bartu A, Saunders W. Domiliciary Detoxification: a cost effective alternative to inpatient treatment. Aust J Adv Nurs 1994;11:4. 
19. Hester RK, Miller WR. Self control training. In: Hester RK, Miller WR, eds. Handbook of alcoholism: effective alternatives. New York: Pergamon Press; 1989. p.141-9.

20. Mattson ME, Allen JP. Research on matching alcoholic patients to treatments: Findings, issues and implications. J Addict Des 1991;11:3349.

21. Miller WR, Sanchez-Craig M. How to have a high success rate in treatment: advice for evaluators of alcoholism programs. Addict 1996;91:779-85.

22. Longabaugh R, Wiritz P, Diclement C, Litt M. Issues in the development of client-treatment matching hypotheses. J Stud Alcohol 1994;12(Suppl):46-59.

23. Ogborne AC, Kaprur BM, Newton, Taylor B. Characteristic of drug users admitted to school detoxification centers. Am J Drug Alcohol Abuse 1992;18:177-86.

24. Collins MN, Burns T, Peter AH, Berk VD, Tubman GFA. Structured Programme for Out-patient Alcohol Detoxification. Br J Psychiatr 1993;156:871-4.

25. Abbott PJ, Quinn D, Knox L. Ambulatory Medical Detoxification for Alcohol. Am J Drug Alcohol Abuse 1995;21(4):549-63.

26. Fleeman ND. Alcohol home detoxification: a literature Review. Alcohol \& Alcoholism. Med Counc Alcohol 1997;32(6):649-56
27. Wiseman EJ, Henderson KL, Briggs MJ. Outcomes of patients in a VA ambulatory detoxification program. Psychiatric Serv 1997;48(2):200-3.

28. Mckay JR, Cacciola JS, Mclellan AT, Alterman AI, Wirtz PW. An initial evaluation of the psychosocial dimensions of the American Society of Addiction Medicine criteria for inpatient versus intensive outpatient substance abuse rehabilitation. J Stud Alcohol 1997;58(3):239-52.

29. Mckay JR, Alterman AI, Mclellan AT, Snider EC. Treatment goals, continuity of care, and outcome in a day hospital substance abuse rehabilitation program. Am J Psychiatry 1994;151(2):254-9.

\section{Correspondência}

Ronaldo Laranjeira

Rua Botucatu, 39

04023-061 São Paulo, SP, Brasil

Tel.: (0xx11) 576- 4341 ou $575-1708$

Fax:(0xx11) 822-1262

E-mail: laranjeira@psiquiatria.epm.br

\section{ANEXO1}

\section{Clinical Institute Withdrawal Assessment for Alcohol, Revised (CIWA-Ar)}

Nome:

Pulso ou FC:

PA:

1. Você sente um mal estar no estômago (enjôo)? Você tem vomitado?

\begin{tabular}{|l|l|}
\hline 0 & Não \\
\cline { 1 - 1 } & Náusea leve e sem vômito \\
\cline { 1 - 1 } 4 & Náusea recorrente com ânsia de vômito \\
\cline { 1 - 1 } 7 & Náusea constante, ânsia de vômito e vômito \\
\cline { 1 - 1 }
\end{tabular}

2. Tremor com os braços estendidos e os dedos separados:

\begin{tabular}{|l|l|}
\hline 0 & Não \\
\cline { 1 - 1 } & Não visível, mas sente \\
\cline { 1 - 1 } & Moderado, com os braços estendidos \\
\cline { 1 - 1 } 7 & Severo, mesmo com os braços estendidos
\end{tabular}

3. Sudorese:

\begin{tabular}{|l|l}
\hline 0 & Não \\
\cline { 1 - 1 } & Facial \\
\cline { 1 - 1 } 7 & Profusa \\
\hline
\end{tabular}

4. Tem sentido coceiras, sensação de insetos andando no corpo, formigamentos pinicações?

Código da questão 8

5. Você tem ouvido sons a sua volta? Algo perturbador, sem detectar nada por perto? Código da questão 8

6. As luzes têm parecido muito brilhantes? De cores diferentes? Incomodam os olhos? Você tem visto algo que tem Ihe perturbado? Você tem visto coisas que não estão presentes?

\begin{tabular}{|c|c|c|c|}
\hline 0 & Não & 4 & Alucinações moderadas \\
\hline 1 & Muito leve & 5 & Alucinações graves \\
\hline
\end{tabular}

Data:

Hora:
7. Você se sente nervoso (a)? (observação)

\begin{tabular}{|c|c|}
\hline 0 & Não \\
\hline 1 & Muito leve \\
\hline 4 & Leve \\
\hline 7 & Ansiedade \\
\hline agudo & \\
\hline 8. Voc & ê sente alg \\
\hline 0 & Não \\
\hline 1 & Muito leve \\
\hline 2 & Leve \\
\hline 3 & Moderado \\
\hline
\end{tabular}

\begin{tabular}{|l|l}
\hline 6 & Extremamente graves \\
\hline 7 & Contínua
\end{tabular}

9. Agitação: (observação)

\begin{tabular}{|l|l}
\hline 0 & Normal \\
\cline { 1 - 1 } 1 & Um pouco mais que a atividade normal \\
\cline { 1 - 1 } 4 & Moderadamente \\
\cline { 1 - 1 } 7 & Constante \\
\hline
\end{tabular}

10. Que dia é hoje? Onde você está? Quem sou eu? (observação)

\begin{tabular}{|c|c|}
\hline 0 & Orientado \\
\hline 1 & Incerto sobre a data, não responde seguramente \\
\hline 2 & Desorientado com a data, mas não mais do que 2 dias \\
\hline 3 & Desorientado com a data, com mais de 2 dias \\
\hline 4 & Desorientado com o lugar e pessoa \\
\hline
\end{tabular}

Escore 